\title{
Design of a 3D control system using PTV-VISSIM to manage Vehicle traffic
}

\author{
Alexi Delgado ${ }^{1}$, Leoncio Cueva-Ruiz ${ }^{2}$ \\ ${ }^{1}$ Mining Engineering Section, Pontificia Universidad Católica del Perú, Lima-Peru, kdelgadov@pucp.edu.pe \\ ${ }^{2}$ Systems Engineering Program, Universidad de Ciencias y Humanidades, Lima-Peru, leocuevar@uch.pe
}

\begin{abstract}
Vehicle congestion has become a conflict that affects an increasing number of countries. To avoid this, it is necessary to design a control system that can benefit those affected by traffic congestion. In this work, PTV-VISSIM will be applied to obtain real-time data when simulating a traffic control system in Lima, Peru. This case study explains the architecture of the prototype which has 2 stages: PTV-VISSIM and the development of the prototype that includes 4 materials (controller, wireless network connection, motion detector and LED traffic lights), components that are critical for the correct functioning of the simulator. Three trials were carried out on different days for the study, based on the traffic flow of each day, which shows that there was a reduction in vehicle traffic. The results could help the authorities to obtain a measure that reduces the time of vehicular traffic congestion at an accessible cost, improving the quality of life of citizens.
\end{abstract}

Key words : 3D control system, Non-intrusive detection, PTV-VISSIM, Wireless network connection.

\section{INTRODUCTION}

As traffic congestion has been increasing, certain consequences have resulted such as slower speeds, longer travel times and an increase in vehicle queues, among others [1]. Although, transport throughout history has been a fundamental contribution to economic development, in recent times the deterioration of public transport has generated chaos in many cities worldwide [2]. As a result, most cities in the world face a variety of problems caused mostly by vehicular traffic due to the growing number of circulating vehicles[3]. In Lima, Peru, for example traffic congestion is one of the most serious concernssince the continuous increase of vehicles in traffic, in private cars and the lack of planning negatively affect the quality of life of the population. As it also occurs in many developing countries which do not have traffic control systems due to the high investment costs involved [4], [5], countries where there are no public or private programs promoting the use of such systems, which leads to a deficient traffic e.g. USA, specifically in Los Angeles, California [6]. However, public transport reforms in Lima and Callao have been largely based on the premise that bus flows cause congestion through the high overcrowding of private vehicles [7].

The simulation of microscopic traffic is the analysis method preferred by researchers in the field, since simulating the elements of the transport system allows an approach near to reality through a single vehicle that behaves as a single agent to allow the configuration of parameters around it at an affordable price and in a recurrent manner [8]. These parameters can be delay time, speed and even the examiner's background and previous literature [9], [10]. However, after analyzing and reviewing the advantages of the different traffic simulation software as PARAMICS and GETRAM/AIMSUN, among others, VISSIM has been chosen as it has a wide range of simulation possibilities and a unique 3D simulation module [8]. Therefore, data will be inserted into the simulation tool to process and organize them in a way that is compatible with VISSIM [11]. The purpose of this software is to simulate and analyze traffic status, also including lane assignment, traffic signs, including vehicles and pedestrians. PTV-VISSIM is suitable for traffic engineering. Therefore, vehicular traffic was controlled by varying the phase shift of the signals. More generally, the traffic signal can be controlled by phase shifting (time shifting), cycle time, and splitting time. In order to investigate signal control, it is necessary and important to consider a series of traffic signals on a highway. Some work has been done recently to move vehicle traffic through an infinite series of traffic lights within the same interval, thus clarifying the effect of cycle time on vehicle traffic as in [12]-[15].

The main purpose of the proposal is the design of a $3 \mathrm{D}$ control system that will allow the management of vehicular traffic in order to improve traffic congestion in the center of Lima, as well as to be a useful tool in the eventuality of an automobile accident or further emergencies.

This work is structured as follows: Section II will explain a brief description of the methodology and the case study of how the prototype is being designed. Likewise, section III will give a detailed explanation of how the prototype will work. Similarly, section IV will go through all the results obtained through the simulation. Lastly, section $\mathrm{V}$ will present the conclusions made by the simulator.

\section{METHODOLOGY}

This section will explain the architecture of the prototype that is has been made for the design of a 3D control system using PTV-VISSIM for the traffic in Lima, Peru.

The architecture of the prototype has 2 stages: PTV-VISSIM simulator and development of the prototype. 


\subsection{Stage 1: PTV-VISSIM Simulator}

VISSIM is a microscopic system, staggered in time, stochastic having a simulation model for the analysis of the operation of the traffic system [16] according to [17]. Most traffic engineers find that there is no significant difference in car size, road width and some other basic parameters of the material facilities. In addition, it is desirable that it be fitted and that it could be completed when the model is structured. However, parameters that reflect driving habits and behaviors greatly influence the outcome, for example, the car tracking model and the lane change model [18], [19].

\subsection{Stage 2: Prototype development}

The present stage has 4 fundamental materials as following:

\section{A. Controllers}

It is a compatible tool which does not require a high volume cabin at the traffic lights for storage, allowing a control strategy suitable for the impending traffic conditions in which the controller functionality is to be applied.

\section{B. Wireless network connection}

It has a wireless connection that is provided in conjunction with the controllers, this will store all types of data so that there is no obstruction or loss of information at the time of operation.

\section{Motion detector}

This stage will have a motion detector that will facilitate and give the instructions to the controller of how many cars are on the road, this will provide the data to ensure if there is a traffic congestion on the tracks.

\section{LED traffic lights}

It has LED televisions that will be responsible for organizing traffic through the lights to regulate traffic this stage will work by giving the order for green light, red light, yellow light, this will serve to prevent vehicle accidents bearing in mind that it will be connected to the traffic light controller.

\section{APPLICATION}

The prototype will have 2 fundamental stages: PTV-VISSIM Simulator and Development of the prototype; which will have a charge for the operation of the simulation, considering that it will evaluate the traffic and determine the advantages for greater control when simulating the streets or highways as shown in Figure 1, which shows the tool that will be used and the development of the prototype.

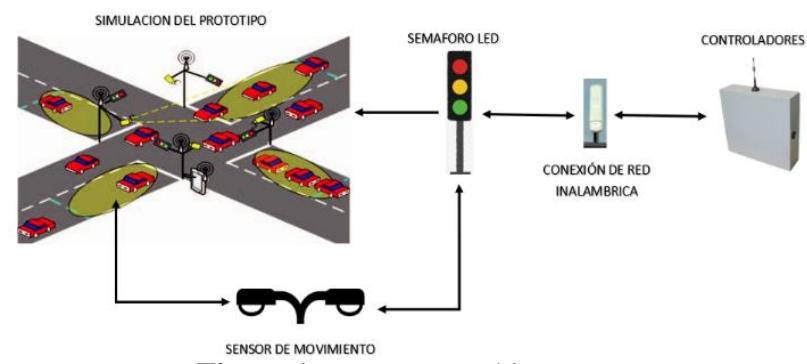

Figure 1: Prototype architecture

\subsection{Stage 1: PTV-VISSIM Simulator}

PTV-VISSIM is a microscopic traffic simulation system developed by PTV, a German company. It is a discrete, time-based, random and behavioral simulation model. The theoretical model adopted by VISSIM is a multi-zone threshold behavior model pro-planned by Professor Wiedemann [8], [20]. In addition, VISSIM has the capability of modelling the interface between multiple traffic modes with car traffic, the ability to generate random vehicles and the flexibility in modelling complex geometries [21].

\subsection{Stage 2: Prototype development}

The prototype includes 4 fundamental materials for this stage (controllers, wireless network connection, motion detector and LED traffic lights), which will have a direct objective for the correct operation of the simulation, taking into account that this will assess the traffic and determine the advantages of having more control when simulating streets or roads as shown in Figure 2.

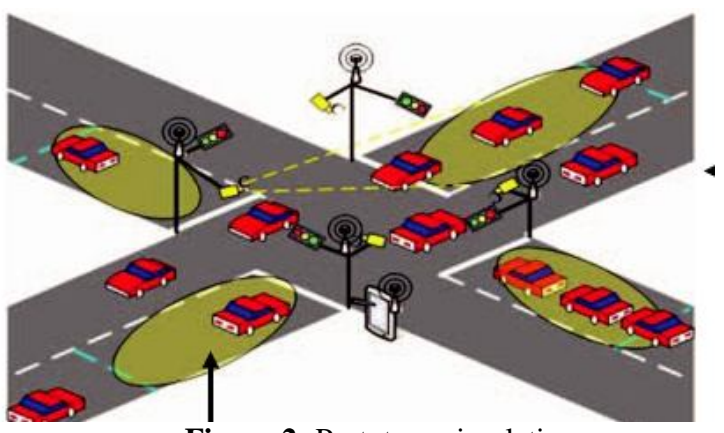

Figure 2: Prototype simulation

\section{A. Controllers}

This tool is an integral part of the control optimization system by which the network administrator can evaluate traffic conditions using sensors and coordinating intersections for better control. However, this will depend on the wireless access point that each traffic light will contain through a wireless connection and an appropriate radio for each sensor, taking into account that each microchip will have its own sensor as shown in Figure 3. 


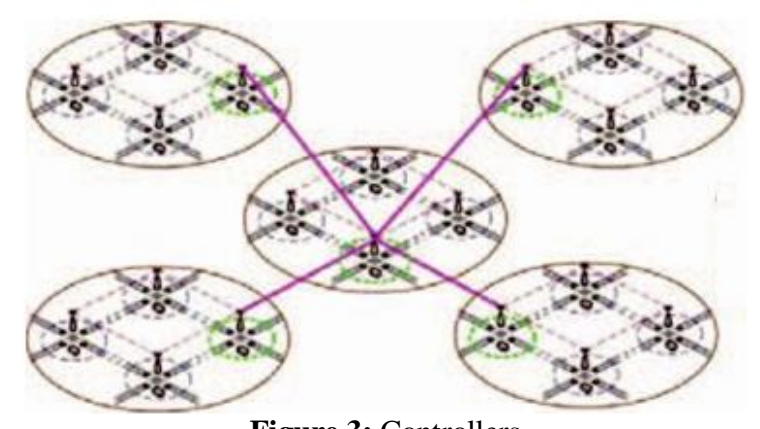

Figure 3: Controllers

\section{B. Wireless network connection}

The development of the prototype will consist of the use of some traffic control devices that will have interconnections, which will be connected to the controller so they can command the operation of the traffic lights. This is taking into account that in conjunction with the sensors, the controller will be able to collect data even if the road is congested; for a better visualization of the proposed scenario see Figure 4.

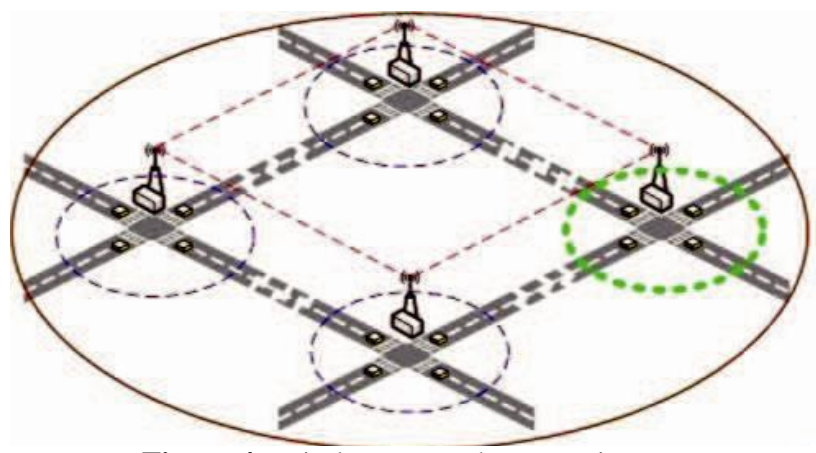

Figure 4: Wireless network connection

\section{Motion detector}

This material will contribute to the detection of vehicles on individual roads. Likewise, due to the camera motion sensors, it will be possible to analyze and identify the cars on the road, which will be linked to the controller which will provide data such as the number of cars or serious traffic congestion, if applicable.

\section{LED traffic lights}

This tool will be in charge of the signalization phase, which will allow the cars to circulate normally without any kind of traffic congestion, since the LED traffic light will give the order to advance or stop based on the data collected from the microchip.

\section{RESULTS AND DISCUSSION}

From the results obtained from the PTV-VISSIM program, it was decided that there would be 3 specific days (Monday, Friday and Sunday); days in which the traffic would increase, thus it was possible to carry out a simulation using extensive data, which was classified considering that the traffic level will be available in 3 different levels for the present work: light, moderate and severe.

The detail of the simulation resulting from each day can be observed below.

\subsection{Simulation of the prototype}

\section{A. Monday Simulation}

The information resulting from Monday can be seen in Table I. The results obtained on 16/09/2019 are described as follows:

a) On Monday at 8:00 AM, there was a 50\% of traffic recorded, which would be considered as moderate vehicle traffic.

b) On Monday at 1:00 PM there was a 10\% of traffic recorded, which would make the traffic of a vehicle more fluid, being considered as light traffic.

c) On Monday at 6:00 PM there was a 50\% of traffic recorded, that would come to be considered as moderate vehicle traffic.

Table 1: Prototype Simulation - Monday

\begin{tabular}{|c|c|c|c|c|c|}
\hline Day 1 & Date & Time & Route & $\begin{array}{c}\text { Traffic } \\
\text { level }\end{array}$ & \% \\
\hline \multirow{3}{*}{ Monday } & \multirow{3}{*}{$16 / 09 / 2019$} & $\begin{array}{c}8: 00 \\
\mathrm{AM}\end{array}$ & $\begin{array}{c}\text { Track } \\
1\end{array}$ & Moderate & 50 \\
\cline { 3 - 6 } & & PM & $\begin{array}{c}\text { Track } \\
1\end{array}$ & Light & 10 \\
\cline { 3 - 6 } & & $\begin{array}{c}6: 00 \\
\text { PM }\end{array}$ & $\begin{array}{c}\text { Track } \\
1\end{array}$ & Moderate & 50 \\
\hline
\end{tabular}

\section{B. Friday Simulation}

The information resulting from Friday can be seen in Table II. The results obtained on 20/09/2019 are described as follows:

a) On Friday at 8:00 AM there was a 50\% of traffic registered, that would come to be interpreted as moderate vehicular traffic.

b) On Friday at 1:00 PM there was a 10\% of traffic registered, which is interpreted as light vehicular traffic.

c) On Friday at 6:00 PM there was a 50\% of traffic registered, so that would come to be interpreted as moderate vehicle traffic.

Table 2: Prototype Simulation - Friday

\begin{tabular}{|c|c|c|c|c|c|}
\hline Day 5 & Date & Time & Route & $\begin{array}{c}\text { Traffic } \\
\text { level }\end{array}$ & $\boldsymbol{\%}$ \\
\hline \multirow{2}{*}{ Friday } & \multirow{2}{*}{$20 / 09 / 2019$} & $8: 00 \mathrm{AM}$ & $\begin{array}{c}\text { Track } \\
1\end{array}$ & Moderate & 50 \\
\cline { 3 - 6 } & & $6: 00 \mathrm{PM}$ & $\begin{array}{c}\text { Track } \\
1\end{array}$ & Light & 10 \\
\cline { 3 - 6 } & & $6: 00 \mathrm{PM}$ & $\begin{array}{c}\text { Track } \\
1\end{array}$ & Moderate & 50 \\
\hline
\end{tabular}




\section{Sunday Simulation}

The information resulting from Sunday can be seen in Table III. The results obtained on 22/09/2019 are described as follows:

a) On Sunday at 8:00 AM there was a 50\% of traffic displayed, that would be understood as moderate traffic.

b) On Sunday at 1:00 PM there was a 50\% of traffic displayed, which would be understood as moderate traffic.

c) On Sunday at 6:00 PM there was a 50\% of traffic displayed, which would be understood as moderate traffic.

Table 3: Prototype Simulation - Sunday

\begin{tabular}{|c|c|c|c|c|c|}
\hline Day 7 & Date & Time & Route & $\begin{array}{c}\text { Traffic } \\
\text { level }\end{array}$ & \% \\
\hline \multirow{4}{*}{ Sunday } & \multirow{3}{*}{$22 / 09 / 2019$} & $\begin{array}{c}8: 00 \\
\mathrm{AM}\end{array}$ & $\begin{array}{c}\text { Track } \\
1\end{array}$ & Moderate & 50 \\
\cline { 3 - 6 } & & $\mathrm{PM}$ & $\begin{array}{c}\text { Track } \\
1\end{array}$ & Moderate & 50 \\
\cline { 3 - 6 } & & $6: 00$ & Track & Moderate & 50 \\
\hline
\end{tabular}

A detailed design of the system was proposed along with the level of traffic in the city. Regarding traffic simulations, the authors point out that currently only about $20 \%$ of all intersections in most cities are signposted due to the high cost of traffic signs. However, it is necessary to consider that the deployment of PTV-VISSIM, which in principle can convert all intersections into signalized intersections, will reduce average travel time by more than $30 \%$ [22]. In this design, a traffic light is proposed that will mitigate vehicular traffic, which is to have free control at the time when traffic is present, providing several benefits such as alleviating traffic congestion, reducing the cost of traffic lights, and reducing the hours lost in traffic congestion as well as the consequences that could result from it (such as the deterioration of food being transported, damage to the mental and physical health of citizens, among others).

\subsection{Methodology}

\section{A. Advantages}

a) Multimodality

The PTV-VISSIM is used for microscopic traffic simulation in both the public and private sectors and scientific research. It has specific behavioral models for motorized transport, bicycle traffic and vehicular traffic, allowing for robust assessments and realistic presentations of all aspects of traffic.

b) $2 \mathrm{D}$ and $3 \mathrm{D}$ visualization

PTV VISSIM has 2D animations and impressive 3D visualizations. Thus, the technical analysis of the traffic becomes friendly and comprehensible.
In general, PTV-VISSIM is a tool that allows the evaluation and planning of both urban and interurban road infrastructure, with a focus on the particularity of the creation of pedestrians as well as vehicles, obtaining detailed numerical results by means of impressive animations through 2D and 3D representations which can simulate diverse scenarios.

Therefore, it is ideal for presenting infrastructure proposals in decision making in a comprehensible and direct way.

\section{CONCLUSION}

This work proposes the design of a traffic control system in the center of Lima, which includes a controller, wireless network connection, motion detector and LED traffic lights, in order to manage the traffic on a high traffic street. The system incorporates an accurate forecast so traffic can be detected and can prepare a strategy to synchronize street signals for better traffic control and improved circulation for the citizens.

The PTV-VISSIM favors the study since it helps to create the prototype and obtain precise data at the time of making the simulation; therefore, it is expected that the PTV-VISSIM will become an adequate control system for Peru.

Likewise, it is expected that the application of artificial intelligence will contribute to an effective control that can be applied in the different cities of the world to assist in a more optimal vehicle traffic system at a low cost and contributing to the lives of the citizens.

\section{REFERENCES}

1. M. Mbodila, E. Obeten, and I. Bassey, Implementation of novel vehicles' traffic monitoring using wireless sensor network in South Africa, Proc. 2015 IEEE Int. Conf. Commun. Softw. Networks, ICCSN 2015, pp. 282-286, 2015.

https://doi.org/10.1109/ICCSN.2015.7296170

2. V. Bax, W. Francesconi and A. Delgado, Land-use conflicts between biodiversity conservation and extractive industries in the Peruvian Andes, Journal of Environmental Management, 232, pp. 1028-1036, 2019. https://doi.org/10.1016/j.jenvman.2018.12.016

3. A. Ronald and M. Ninacansaya, Analysis and Design System Using Vehicular Traffic Control Traffic Lights With Intelligent Technology Arduino, p. 79, 2016.

4. A. Campuzano, R. López, and J. Lima, Cooperative estimation of vehicular traffic using mobile applications, in Proceedings - 2015 41st Latin American Computing Conference, CLEI 2015, 2015. https://doi.org/10.1109/CLEI.2015.7359461

5. R. P. Jagali, Traffic Queuing Analysis on Chord Road , Vijayanagar , Bengaluru using PTV Vissim Software,vol. 1, no. 9, pp. 14-19, 2016.

6. $\mathrm{BBC}$, Las ciudades y países con el tráfico más congestionado de América Latina - BBC News Mundo, 21-Feb-2017.

7. M. Sacasqui, J. Luyo and A. Delgado, A Unified Index for Power Quality Assessment in Distributed 
Generation Systems Using Grey Clustering and Entropy Weight, 2018 IEEE ANDESCON, ANDESCON 2018 - Conference Proceedings, 8564631, 2018

8. L. Yang and W. Lan, On secondary development of PTV-VISSIM for traffic optimization, 13th Int. Conf. Comput. Sci. Educ. ICCSE 2018, no. Iccse, pp. 542-547, 2018. https://doi.org/10.1109/ICCSE.2018.8468743

9. A.Delgado,A.Aguirre, E.Palomino andG.Salazar, Applying triangular whitenization weight functions to assess water quality of main affluents of Rimac river, In Proceedings of the 2017 Electronic Congress, E-CON UNI 2017, 2018-January, pp. 1-4, 2018.

10. Koukol, M., 2012. Přehled současných vědeckých a aplikačních výsledků $v$ ř́zení světelné signalizace pomocí fuzzy logiky [Výzkumná zpráva č. 2327]. Praha: ÚTIA AVČR, pp. 41.

11. I. Karakikes, M. Spangler, and M. Margreiter, Designing a Vissim-Model for a motorway network with systematic calibration on the basis of travel time measurements, Transp. Res. Procedia, vol. 24, pp. 171-179, 2017. https://doi.org/10.1016/j.trpro.2017.05.086

12. K. Komada and T. Nagatani, Modeling and simulation for vehicular traffic in city network controlled by signals, TIC-STH'09 2009 IEEE Toronto Int. Conf. - Sci. Technol. Humanit., pp. 66-71, 2009.

13. B. A. Toledo, V. Munoz, J. Rogan, and C. Tenreiro, Modeling traffic through a sequence of traffic lights, Phys Rev E, vol. 70, pp. 016-107, Nov 2001. https://doi.org/10.1103/PhysRevE.70.016107

14. B. A. Toledo, E. Cerda, J. Rogan, V. Munoz, C. Tenreiro, R. Zarama, and J. A. Valdivia, Universal and nonuniversal features in a model of city traffic, Phys Rev E, vol. 75, pp. 026-108, Feb 2007. https://doi.org/10.1103/PhysRevE.75.026108

15. T. Nagatani, Self-similar behavior of a single vehicle through periodic traffic lights, Physica A, vol. 347, pp. 673-682, Mar 2005 https://doi.org/10.1016/j.physa.2004.08.007

16. VISSIM Version 3.7 Manual (2003). PTV Planug Transport Verkehr AG. Innovative Transportation Concepts. December

17. W. Zhizhou, S. Jian, and Y. Xiaoguang, Calibration of VISSIM for Shanghai Expressway using genetic algorithm, Proc. - Winter Simul. Conf., vol. 2005, pp. 2645-2648, 2005.

18. J. Leng, Y. Zhang, and M. Sun, VISSIM-Based simulation approach to evaluation of design and operational performance of U-turn at intersection in China, Proc. - 2008 Int. Work. Model. Simul. Optim. WMSO 2008, pp. 313-318, 2009. https://doi.org/10.1109/WMSO.2008.38

19. Nikiforos Stamatiadis, Teja Banu Kala. U-Turns At Signalized Interscetions.Research Report KTC-04-12/SPR 258-03-3F

20. P Karlsruhe, P Ag, VISSIM 3.40: user manual

21. S. M. P. Siddharth and G. Ramadurai, Calibration of VISSIM for Indian Heterogeneous Traffic
Conditions, Procedia - Soc. Behav. Sci., vol. 104, pp. 380-389, 2013. https://doi.org/10.1016/j.sbspro.2013.11.131

22. R. Zhang et al., Virtual Traffic Lights: System Design and Implementation, IEEE Veh. Technol. Conf., vol. 2018-Augus, pp. 1-5, 2019 